\section{"Where's My Mentor?!" Characterizing Negative Mentoring Experiences in Undergraduate Life Science Research}

\author{
Lisa B. Limeri, ${ }^{\dagger}$ Muhammad Zaka Asif, ${ }^{\ddagger \neq}$ Benjamin H. T. Bridges, ${ }^{\prime \neq}$ David Esparza, ${ }^{\neq \$}$ \\ Trevor T. Tuma, ${ }^{\dagger \neq}$ Daquan Sanders, ${ }^{\dagger}$ Alexander J. Morrison, ${ }^{\dagger}$ Pallavi Rao, ${ }^{\dagger}$ \\ Joseph A. Harsh," Adam V. Maltese," and Erin L. Dolan ${ }^{\dagger *}$ \\ 'Department of Biochemistry and Molecular Biology, University of Georgia, Athens, GA 30602; \\ sDepartment of Biological Sciences, University of Texas at El Paso, El Paso, TX 79968; "Department \\ of Biology, James Madison University, Harrisonburg, VA 22802; 'Center for Research on Learning \\ and Technology, Department of Curriculum and Instruction, Indiana University, Bloomington, \\ IN 47405
}

\begin{abstract}
Undergraduate research experiences in science, technology, engineering, and mathematics fields are championed for promoting students' personal and professional development. Mentorship is an integral part of undergraduate research, as effective mentorship maximizes the benefits undergraduates realize from participating in research. Yet almost no research examines instances in which mentoring is less effective or even problematic, even though prior research on mentoring in workplace settings suggests negative mentoring experiences are common. Here, we report the results of a qualitative study to define and characterize negative mentoring experiences of undergraduate life science researchers. Undergraduate researchers in our study reported seven major ways they experienced negative mentoring: absenteeism, abuse of power, interpersonal mismatch, lack of career support, lack of psychosocial support, misaligned expectations, and unequal treatment. They described some of these experiences as the result of absence of positive mentoring behavior and others as actively harmful behavior, both of which they perceive as detrimental to their psychosocial and career development. Our results are useful to mentors for reflecting on ways their behaviors might be perceived as harmful or unhelpful. These findings can also serve as a foundation for future research aimed at examining the prevalence and impact of negative mentoring experiences in undergraduate research.
\end{abstract}

\section{INTRODUCTION}

Undergraduate research experiences (UREs) are championed for their potential to promote student learning and development in science, technology, engineering, and mathematics (STEM) fields (Laursen et al., 2010; Lopatto and Tobias, 2010; National Academies of Sciences, Engineering, and Medicine, 2017). Mentoring by more experienced scientists, such as faculty, graduate students, and postdoctoral researchers, is considered a key component of successful UREs (Thiry and Laursen, 2011; ByarsWinston et al., 2015; Estrada et al., 2018). Multiple studies have shown that mentors and mentoring support play a critical role in undergraduate researchers' personal and professional development (Thiry and Laursen, 2011; Aikens et al., 2017, 2016; Hernandez et al., 2017). Although some of this research has revealed that mentors can be a source of negative experiences (Goodyear et al., 1992; Thiry and Laursen, 2011), there has been little systematic investigation of negative or problematic aspects of mentoring in undergraduate research.

A handful of studies investigating mentoring in UREs have acknowledged variation in the quality of mentoring, such as mentors being absent, setting unrealistic expectations, and not providing enough guidance (Bernier et al., 2005; Dolan and Johnson, 2010; Harsh et al., 2011; Thiry and Laursen, 2011). This is not surprising, as mentoring
Joel K. Abraham, Monitoring Editor Submitted Feb 11, 2019; Revised Jul 23, 2019 ; Accepted Aug 30, 2019

CBE Life Sci Educ December 1, 2019 18:ar61 DOI:10.1187/cbe.19-02-0036

FCo-second authors (listed in alphabetical order) *Address correspondence to: Erin L. Dolan (eldolan@uga.edu).

(c) 2019 L. B. Limeri et al. CBE-Life Sciences Education ( 2019 The American Society for Cell Biology. This article is distributed by The American Society for Cell Biology under license from the author(s). It is available to the public under an Attribution-Noncommercial-Share Alike 3.0 Unported Creative Commons License (http://creativecommons.org/licenses/ by-nc-sa/3.0)

"ASCB®" and "The American Society for Cell Biology ${ }^{\circledR}$ " are registered trademarks of The American Society for Cell Biology. 
is an interpersonal relationship, and all interpersonal relationships can include dysfunctional elements or problematic events (Duck, 1994). Scholars of mentoring in the workplace have long recognized that mentoring quality exists as a continuum (Ragins et al., 2000) and have referred to less favorable interactions with mentors as "negative mentoring experiences" (Kram, 1983; Scandura, 1998; Eby et al., 2000). It is important to note that negative mentoring experiences can refer to problematic aspects of an otherwise positive relationship and do not necessarily mean that the entire relationship is negative or harmful (Scandura, 1998; Simon and Eby, 2003).

Scandura (1998) was among the first to define negative mentoring experiences, which she termed "dysfunctional mentoring," drawing primarily from research on the development and functioning of other relationships, such as friendship and marriage. Specifically, Scandura integrated Duck's categorization of the "dark side" of relationships as having good or bad intent (Duck, 1994) with Kram's categorization of mentoring as providing career-related support and psychosocial, or emotional or counseling-related, support (Kram, 1985). For instance, mentors who bully their protégés (i.e., mentees) are perceived as having bad intent with primarily psychosocial effects, while mentors who do not have the skills, connections, or other resources to help their mentees in their career pursuits are perceived as having good intent with primarily career-related effects.

Eby and colleagues (2000) elaborated on this work in their study of 156 workplace mentees, more than 50\% of whom reported at least one negative mentoring experience and who collectively reported a total of 168 distinct negative mentoring experiences. Through analysis of these experiences, Eby and colleagues generated a taxonomy of 15 types of negative mentoring that fit five major categories: mentor-mentee mismatch, including mismatched work-styles, values, and personalities; distancing behavior, such as self-absorption of the mentor and neglect by the mentor; manipulative behavior, such as the mentor inappropriately delegating work to the protégé or taking credit for the mentee's work; lack of mentor expertise, including both technical and interpersonal incompetence; and general dysfunctionality, such as mentors having negative attitudes or personal problems.

The phenomena of abusive supervision and workplace incivility also provide useful ways of thinking about how individuals might experience negative mentoring. Abusive supervision is defined as subordinates' perceptions of the extent to which supervisors engage in sustained, hostile verbal and nonverbal behaviors (Tepper, 2000). Examples include telling a subordinate that his or her thoughts and feelings are "stupid" or putting down the subordinate in front of others. Incivility is defined as low-intensity antisocial behavior, such as being rude, ignoring, or excluding (Cortina et al., 2001; Schilpzand et al., 2016). Incivility is characterized as having an ambiguous intent to harm, meaning that the instigator can simply be ignorant that his or her behavior is being negatively perceived. Incivility is neutral with respect to any difference in power or authority between the instigator and target, meaning that uncivil behavior can originate from supervisors, peers, and subordinates.

To our knowledge, there has been no systematic effort to identify, describe, or measure negative mentoring experiences in undergraduate STEM research. Understanding the extent to which negative mentoring experiences occur in undergraduate research is critical because of their potential to cause harm. Mentees who experience negative mentoring in the workplace report decreased job satisfaction and increased turnover intentions and stress (Eby and Allen, 2002). In fact, negative mentoring at work can be so damaging that mentees who experience it may be worse off than if they had no mentor at all (Ragins et al., 2000). The relationship between negative mentoring and undesirable mentee outcomes (e.g., intentions to leave a job) is strongest for formally initiated mentoring relationships-those that are "assigned." This is concerning, because URE mentoring relationships are typically formed through a formal process; either a faculty member assigns an undergraduate to a graduate or postdoctoral mentor or an undergraduate is assigned to a faculty member's research group in a formal research program.

Even more worrisome is the notion that negative mentoring may be more harmful for undergraduates from historically underrepresented backgrounds. Studies investigating positive outcomes of mentoring have shown that UREs are particularly beneficial for underrepresented students (Thiry and Laursen, 2011; Estrada et al., 2018). The effectiveness of UREs for underrepresented students may hinge on the capacity of these experiences to promote a sense of fit with the scientific community (Hurtado et al., 2008, 2011; Estrada et al., 2011, 2018). Therefore, negative mentoring experiences may disproportionately harm these students.

To begin to address this gap in knowledge, we conducted a qualitative study to understand how undergraduate life science researchers experience negative mentoring (Creswell, 2012). We focus on UREs in the life sciences because there have been multiple national calls to make research experiences an integral component of undergraduate biology education (American Association for the Advancement of Science, 2011) and the majority of undergraduate students in STEM are in the life sciences (Chen, 2013). We identified 33 undergraduates who conducted life science research for at least one semester or summer in the past year, who represented a range of institutions and personal characteristics, and who rated their experiences with their research mentors as "less than ideal." We interviewed these undergraduates about the mentoring behaviors, characteristics, or events that prompted their rating, including whether they perceived these experiences as affecting their personal (psychosocial) or professional (career-related) growth. We then used a combination of conventional and directed qualitative content analysis (Hsieh and Shannon, 2005; Saldana, 2015). First, we conducted an initial qualitative analysis of undergraduates' descriptions of their negative mentoring experiences (Charmaz, 2006), keeping in mind previous descriptions of negative mentoring experiences from workplace settings (i.e., directed content analysis) but remaining open to experiences that emerged from the data (i.e., conventional content analysis). Consistent with conventional content analysis, we categorized undergraduates' descriptions into seven main ways undergraduates in our sample experienced negative mentoring. Consistent with directed content analysis, we completed our analysis by checking for alignment between our results and theory and reports of negative mentoring experiences in the workplace (Scandura, 1998; Eby et al., 2000).

Our results can be used by practitioners to reflect on how their mentoring behaviors might be perceived and experienced 
by undergraduate researchers. Our results also begin to delineate the construct of negative mentoring experiences of undergraduate researchers; this is a critical first step for developing a quantitative measure of negative mentoring experiences in undergraduate research, which will enable future research.

\section{METHODS}

This study was reviewed and determined to be exempt by the University of Georgia Institutional Review Board (STUDY00004954).

\section{Participants}

We chose to study negative mentoring from the perspective of the mentee (i.e., undergraduate researcher) for several reasons. First, directly observing mentoring would be intrusive and impractical, and negative mentoring may not always be visible to observers. Second, mentors may not be aware that particular behaviors are problematic and may not be willing to report less than ideal behavior. Finally, mentee perceptions of mentoring have been shown to fundamentally alter these relationships and to have long-term effects on mentee outcomes (Scandura, 1998; Eby et al., 2008, 2010).

We identified and recruited undergraduate researchers in the life sciences who experienced negative mentoring via a screening survey distributed by email. Specifically, we distributed the email with a link to the survey, which was hosted on the secure survey service Qualtrics, to undergraduate research groups and points of contact (e.g., academic advisors) at colleges and universities in the United States. We asked these individuals to distribute the email to undergraduate researchers in their programs. As data collection progressed, we also used "snowball sampling," asking participants to nominate individuals they knew who might fit the study criteria. We then sent the screening survey to the nominees.

The purpose of the screening survey was to identify undergraduate researchers who met our selection criteria and could best report on negative mentoring experiences per se (Morse et al., 2002). First, respondents had to confirm that 1) they were life sciences majors; and 2) they had conducted research in a faculty member's research group (i.e., not a course-based undergraduate research experience, or CURE) for at least one term (i.e., summer, semester, quarter) within the past year. As noted earlier, we limited our study to life science research because of national calls to involve undergraduates in research in the life sciences. In addition, we expected research experiences and mentoring norms to differ by discipline, and we wanted to control for this difference to some extent. Our third and final selection criterion was that participants had to rate their experience with a research mentor as less than ideal, meaning that they had direct experience with the phenomenon of interest. Thus, we included a single item on the survey asking potential participants to rate their experiences with their research mentor on an 11-point scale from -5 to +5 . We received 43 responses to the screening survey, and we selected 35 individuals to interview based on their ratings of their experiences with their research mentors as +3 or lower.

We ultimately interviewed 33 life science undergraduate researchers whose ratings span the range of -5 to +3 (two of the survey respondents never responded to requests to schedule interviews). This sample included 22 women and 11 men from the following racial/ethnic groups: 14 white, nine Hispanic or Latinx, three Asian, two African-American, one American Indian or Alaskan Native, and one North African/Middle Eastern. Two participants identified with more than one racial or ethnic group, and five participants preferred not to disclose their racial/ethnic identity. Participants conducted research at 10 institutions throughout the United States: seven public and three private institutions, of which nine were research universities, including one Hispanic-serving institution, and one was a liberal arts college according to the Carnegie Classification of Institutions of Higher Education. We did not ask participants to report any information about their mentors (e.g., mentor career stage) or their research programs, because examining the influence of these factors was beyond the scope of this research. It was clear from the interviews that undergraduates reported negative experiences with both graduate student and faculty mentors. We also wanted participants to feel as comfortable as possible reporting honestly and openly about their experiences, without concern that their mentors would know they had done so.

\section{Data Collection}

To gain insight into undergraduate researchers' experiences with negative mentoring, pairs of authors L.B.L., M.Z.A., B.H.T.B., D.E., T.T.T., and D.S. conducted semistructured interviews with undergraduate researchers who met the study criteria (Fontana and Frey, 2000). Conducting the interviews in pairs helped to ensure consistency of interview style across interviews and also ensured that the interview pair always included one undergraduate student (B.H.T.B., D.E., T.T.T., and D.S. were undergraduate researchers themselves at the time the interviews were conducted). The interviews lasted 30-60 minutes and were conducted in person or via videoconference. While participants were asked to focus on a single mentor in their responses, some referred to multiple mentors and other members of their research group in the course of conversation; these comments were included in the data set. Interview questions focused on gaining in-depth understanding of any negative and problematic aspects of the mentoring that undergraduates experienced during their research, including mentor behaviors and characteristics and mentoring situations and events (see the Supplemental Material for the interview guide). Participants were compensated with a \$25 Amazon gift card.

\section{Data Analysis}

Interviews were audio-recorded, transcribed verbatim, and checked for accuracy. All identifying information about participants and any people with whom they worked during their research were replaced with pseudonyms. Interview transcripts were imported into MaxQDA (Verdi Software, Berlin, DE) for qualitative content analysis. The first phase of analysis involved open coding, or attaching codes or labels to sections of text that represented distinct ideas or meanings (Saldana, 2015). The coding was carried out by researcher-authors L.B.L. (postdoctoral associate), M.Z.A. (graduate student), and B.H.T.B., D.E., T.T.T., and D.S. (undergraduate students). All have experience working in mentor-mentee relationships in the life sciences. All were also familiar with previous research on negative mentoring in the workplace, abusive supervision, and workplace incivility (Scandura, 1998; Eby et al., 2000; Schilpzand et al., 2016; 
Tepper et al., 2017). Familiarity with this literature helped the researchers to identify and ascribe meaning to various types of negative mentoring, while the open-coding process helped to ensure the analysis reflected the undergraduates' lived experiences with negative mentoring and was not limited to findings about negative mentoring in the workplace.

Each transcript was independently read in its entirety by pairs of researchers. Each researcher identified sections of the text (i.e., quotes) that communicated distinct ideas and assigned codes to capture those ideas. The researchers then met to discuss their initial coding by working through each transcript, taking turns explaining the reasons for coding each quote, coming to consensus regarding which data corresponded with which code, and revising codes as needed. The definitions of codes evolved over time as examples accumulated. As decisions were made about dividing, combining, or redefining codes, all previously coded transcripts were revisited to apply the refined codes to the data. Thus, the coding process was highly iterative and collaborative, involved prolonged engagement with the data, and always occurred in teams that included at least two researchers to allow for constant comparison of the interpretations of the data. Furthermore, pairs of researchers took turns working with each other (i.e., no pair worked together all of the time) to ensure consistency of analysis across the researchers. This process resulted in a final codebook, or collection of codes, that describes the particular ways negative mentoring manifested in the lived experiences of the undergraduates in our sample.

The researchers then reviewed the codebook and the coded data to cluster the codes into categories that reflected the common ways that undergraduate researchers experienced negative mentoring. As each category emerged, the researchers defined the category and its hallmarks and revisited the data to ensure the category reflected what undergraduates reported. Through this process, we identified seven main categories. We concluded our analysis by determining the extent to which each category fit with Scandura's framework of dysfunctional mentoring (Scandura, 1998). Specifically, we revisited the data associated with each category to determine whether undergraduates described their experiences as actively harmful experiences or as absence of positive experiences. We also examined the data associated with each theme to determine whether undergraduates expressed concern about their career development or psychosocial development as a result of what their mentors did or neglected to do. Throughout this entire process, the results in progress were presented to undergraduate students, graduate students, postdoctoral associates, and faculty who are members of the Biology Education Research Group at the University of Georgia. This peer debriefing provided an impartial perspective that helped to improve the trustworthiness of the findings and conclusions (Lincoln and Guba, 1985; Hsieh and Shannon, 2005). Furthermore, the involvement of authors J.A.H. and A.V.M. was limited to providing data for pilot testing the analysis, discussion of the results, and reviewing the article. Thus, they provided an "outsider" perspective on the trustworthiness of the findings and conclusions.

\section{RESULTS}

Here we describe the seven categories that reflect the common ways undergraduate researchers experienced negative mentor- ing, listed in alphabetical order and summarized in Table 1: 1) absenteeism, 2) abuse of power, 3) interpersonal mismatch, 4) lack of career and technical support, 5) lack of psychosocial support, 6) misaligned expectations, and 7) unequal treatment. For each category, we describe how the category manifested in undergraduates' lived experience. We also offer our interpretation of whether undergraduates perceived particular negative mentoring experiences as 1 ) the absence of positive mentoring or as actively harmful mentoring and 2) affecting their careerrelated or psychosocial development.

\section{Absenteeism}

Almost all of the undergraduates in our sample ( $n=31$ of 33 ) experienced mentor absenteeism, meaning the physical or intellectual absence of their mentors. Many undergraduates expected that they would be able to meet regularly with their mentors and that their mentors would be able to offer guidance when needed. Undergraduates described many different reasons for why mentors were physically absent, such as traveling for work or needing to address personal issues. Undergraduates also described many instances when mentors were on campus or in the office or lab but were unavailable to offer them intellectual guidance or oversight of their work. It was common for undergraduates to describe their mentors as "very busy" regardless of the mentor's reported career stage (e.g., graduate student, faculty member). Undergraduates perceived their mentors as having many other commitments that prevented or limited regular communication. When mentors were out of the office or otherwise unavailable, undergraduates often attempted to reach them by email but did not receive responses. Some undergraduates described instances when mentors appeared willing to meet with their mentees, but the meetings never came to fruition. One undergraduate remarked,

I tried emailing [the faculty mentor] multiple times... Sometimes she would say, "Yeah, let me just have some time" or sometimes she would just ignore my emails completely. When I confronted her in person about it, she'd be like, "Yeah, let me just set up a meeting with you," and the meeting never happened.... I would have to literally wait outside her office door to see if she was even in there.

Undergraduates expressed frustration about being unable to contact or communicate with their mentors. Some focused on the proximal effects on their scientific progress, such as how their research went off track without mentor guidance. This even happened in situations in which the undergraduate had a graduate student mentor in addition to a faculty mentor. In one instance, the faculty mentor was not available to offer guidance, resulting in the graduate student and undergraduate doing research that the faculty mentor ultimately deemed as "wrong." The undergraduate lamented that the scientific missteps could "have been avoided by [the faculty mentor] actually coming into the lab."

Other undergraduates focused on more distal effects, such as how their mentors' absence played into their career decision making. They took their mentors' absence as a sign that they were not worthy of attention or doing sufficiently interesting, valuable, or meritorious work. These undergraduates 
TABLE 1. Summary of the seven main forms of negative mentoring experienced by undergraduates in our studya

\begin{tabular}{|c|c|}
\hline Categories and definitions & Manifestations \\
\hline $\begin{array}{l}\text { Absenteeism }(n=31) \\
\text { Mentor is physically or intellectually unavailable to offer } \\
\text { guidance, feedback, or support to mentee. }\end{array}$ & $\begin{array}{l}\text { Absence due to conference travel, fieldwork, or other commitments } \\
\text { Too busy to offer guidance, oversight, or feedback } \\
\text { Lack of response to meeting requests or emails }\end{array}$ \\
\hline $\begin{array}{l}\text { Abuse of power }(n=29) \\
\text { Mentor acts in ways that take advantage of position of power } \\
\text { or are inappropriate given the differences in rank or } \\
\text { position between mentor and mentee. }\end{array}$ & $\begin{array}{l}\text { Public humiliation, belittling, and name-calling } \\
\text { Overly harsh reprimands or ill temper } \\
\text { Intimidation } \\
\text { Implicit or explicit threats of repercussions } \\
\text { Coercion } \\
\text { Micromanagement } \\
\text { Excessive judgment } \\
\text { Credit taking and blaming }\end{array}$ \\
\hline $\begin{array}{l}\text { Interpersonal mismatch }(n=12) \\
\text { Mentor and mentee have dissimilar personalities, work styles, } \\
\quad \text { or communication preferences. }\end{array}$ & $\begin{array}{l}\text { Mismatched personalities } \\
\text { Different work styles } \\
\text { Different communication styles }\end{array}$ \\
\hline $\begin{array}{l}\text { Lack of career and technical support }(n=33) \\
\text { Mentor fails to provide needed career guidance or technical } \\
\text { advice or is not invested in mentee's research. }\end{array}$ & $\begin{array}{l}\text { Insufficient career guidance } \\
\text { Insufficient technical instruction } \\
\text { Insufficient safety training } \\
\text { Lack of investment in the mentee's research } \\
\text { Lack of investment in the mentee's career development }\end{array}$ \\
\hline $\begin{array}{l}\text { Lack of psychosocial support }(n=19) \\
\text { Mentor fails to provide encouragement or acts in ways that } \\
\text { undermine the sense of trust in and respect for the mentee. }\end{array}$ & $\begin{array}{l}\text { Insufficient encouragement } \\
\text { Lack of trust in the mentee and his or her abilities } \\
\text { Lack of investment in the mentee as a person } \\
\text { Lack of investment in the mentoring relationship } \\
\text { Other interpersonally inappropriate behaviors (giving unsolicited advice, } \\
\text { sharing intimate details, insulting or gossiping about others) }\end{array}$ \\
\hline $\begin{array}{l}\text { Misaligned expectations }(n=23) \\
\text { Mentor has unspoken or unreasonable expectations of the } \\
\text { mentee or expectations that are misaligned with those of } \\
\text { the mentee. }\end{array}$ & $\begin{array}{l}\text { Unreasonable mentor expectations of the mentee } \\
\text { Misaligned expectations between mentor and mentee } \\
\text { Misaligned expectations about student's ability or knowledge level } \\
\text { Misaligned expectations about structure of mentoring relationship }\end{array}$ \\
\hline $\begin{array}{l}\text { Unequal treatment }(n=12) \\
\text { Mentor treats the mentee differently based on mentee personal } \\
\text { characteristics or choices or mentor preferences. }\end{array}$ & $\begin{array}{l}\text { Discrimination } \\
\text { Favoritism }\end{array}$ \\
\hline
\end{tabular}

aWe define each form and indicate how many undergraduates in our study reported experiencing each form (left column). We also list the main ways each form manifested in undergraduates' lived experiences (right column).

questioned whether they were cut out for a career in science, as one undergraduate explained:

It was very frustrating. I felt like I was left alone in the dark most of the time, and it was very discouraging also because it made me feel like, well maybe if I can't work for [my mentor] and [another student in lab] can, then maybe this isn't really cut out for me. It made me question my career choice.

Undergraduates with absent mentors felt that they missed opportunities for professional guidance (career effects) and also saw their work and themselves as unworthy of attention (psychosocial effects). Given the nature of absenteeism, students felt these consequences resulted from the absence of positive mentoring rather than as an actively harmful experience.

\section{Abuse of Power}

Most undergraduates in our sample $(n=29)$ described situations in which mentors appeared to take advantage of their positions of power or act in ways that were inappropriate given the differences in rank or position between the faculty, graduate, or postdoctoral mentor and the undergraduate mentee. Undergraduates described how their mentors' behaviors caused feelings of inferiority, intimidation, humiliation, embarrassment, and other forms of discomfort, compromising their psychosocial well-being and development. Undergraduates trusted their mentors to give them valuable guidance and to recognize and take responsibility for instances when their guidance was less valuable. For example, one undergraduate recalled being humiliated in front of her lab group while presenting a paper that her mentor had selected for her. Even though, during the course of discussion, her mentor recognized that the paper was too challenging, the mentor did not relent in questioning her and then blamed her for not selecting an easier paper:

I was a second semester freshman when I started, I had no idea what organic chemistry was.... [I was] drilled questions about random organic chemistry that I honestly had no idea ... That was really annoying and humiliating... I was just being humiliated for three whole hours and at the end of it, it was like, "Oh, I should have chosen an easier paper."

Undergraduates expected to be corrected, but felt their mentors sometimes handled addressing their mistakes poorly. Some described instances in which mentors went beyond pointing out and correcting their mistakes to yelling at them, belittling them, 
calling them names, or threatening to replace them with another undergraduate if they made another mistake. For example, one undergraduate recalled how he was harshly reprimanded and made to feel inferior for a mistake he made because his mentors did not provide enough guidance:

I repeatedly asked for help from the $\mathrm{PhD}$ student and from the assigned mentor that I had ... I was ignored multiple times. And then ... I accidentally malfunctioned the machine and the machine broke. I was completely blamed for it... I was called into the office and I was just reprimanded. They told me, "how could I be so dumb?" ... The way he talked to me, it made me feel pretty inferior.

Some undergraduates reported that these behaviors and situations created a culture of intimidation and fear in their labs. Multiple undergraduates noticed how other members of their labs were afraid of their faculty mentors because of their confrontational manner or their tendency to lose their temper and "be rough" with people. Undergraduates also feared longer term repercussions of making mistakes, leaving the lab, or attempting to address problems with their mentors. For instance, undergraduates expressed concern that a poor experience with a mentor would result in a poor grade for their research and even poor grades in other courses that the mentor taught.

Despite the discomfort undergraduates felt with their mentors' behaviors, they felt they had little control and few options to improve their situations. They recognized that they had to maintain some sort of functional relationship with their faculty mentor to ensure that they would have access to future opportunities. They expressed concern that they might not receive a good letter of recommendation or they might not be considered for future research opportunities. Undergraduates described feeling obligated to work many more hours than required by their programs to meet their mentors' expectations, as described by this student:

I do remember my future being dependent on it, because [my mentors] were telling me that these things I needed to get from them to get into grad school were dependent on how good I was doing in their lab, a.k.a. how long I was going to be there and if I was getting things done. So I don't feel like my grade was necessarily as much in peril as my future was. Which was a lot more terrifying and cause to be there later hours.

One undergraduate described a particularly extreme situation. Her mentor would track the locations and activities of the lab members. If she did not report her location, her mentor would punish other lab members by depriving them of equipment or other resources necessary for their research:

Monday through Saturday from six in the morning to seven p.m. I would have to mark when I was home. I would have to mark when I was at a dentist appointment. I would have to mark if I was having lunch. Sometimes, we would even have to say exactly where we were... He would send out an email with everybody in the group and he would speak negatively about whichever individuals were not updating their tracker correctly. Whoever was not doing it correctly would lose resources. He wouldn't talk to them until they finished it. He wouldn't allow them to have access to things in the lab. He would take things away. He would block them out of things... [When I didn't update my tracker] he had started putting me on blast on the group emails... He would say, "Hello everyone, you won't have access to whatever thing until [the undergraduate] updates her tracker." And, "Sorry for the inconvenience everyone, [the undergraduate] messed up on her tracker."

Undergraduates also experienced less extreme circumstances and discussed how these undermined or prevented their learning or development. For instance, some undergraduates were only allowed to observe others doing research, even after spending a full semester observing. Other undergraduates reported only being allowed to read and present papers, but not to carry out any lab work. In some cases, mentors gave undergraduates reasons for limiting their activity, explaining that undergraduates were simply not allowed to do lab work or that they had to "pay their dues" before being allowed to do more meaningful work. Multiple undergraduates described how their mentors passed judgment on their potential to be scientists, noting that they did not have "what it takes" to be successful in science, as one undergraduate explained:

I talked to [my mentor] and I was like, "I think I need to do something more. I'm interested in learning something else." She said, "Oh, you have to be worthy. You have to earn this. Science just doesn't come to you. You have to be worthy of science." ... I know science doesn't just come to anyone, but at the same time, I felt like I was trying my best, I was trying to get to that level, but I was being limited by the project that the lab was giving me.

Finally, a few undergraduates described how their mentors abused their positions of power by taking credit for their work or blaming them for mistakes, misunderstandings, or miscommunications. This appeared to occur in situations in which a graduate student was serving as the day-to-day mentor of the undergraduate and would speak on the mentee's behalf or otherwise represent them to the faculty mentor. Undergraduates described instances when they had a successful scientific result for which their graduate student mentor took credit. Undergraduates were not expecting to get credit in place of a graduate student, but rather in addition to the graduate student, because they felt they had contributed to the project. In other instances, undergraduates felt like they took the fall for a mistake or misunderstanding that their graduate student mentors could have prevented. For example, one undergraduate recounted how the graduate student mentor could have helped shoulder the blame for a mistake, but opted not to intervene:

I didn't know anything about this [lab technique], so even if there was something wrong, I would not be able to catch it because of my amount of knowledge as an undergraduate.... [My graduate student mentor] willingly let me email a paper, where I had the whole step wrong, to my professor, and to me, told me it looked good.... So, she just let me send him [the faculty mentor] wrong information. He was yelling at me. She was CC'd in all these emails. Not once did she say, "Oh, I looked over this paper with her. I didn't know what was wrong. 
Do you mind explaining to both of us?" That would have been nice, but she just kept letting me take the blame."

Undergraduates universally perceived these experiences as actively harmful and having both career-related and psychosocial effects. For example, when students perceived that their mentors prevented them from engaging in meaningful, developmental activities in the lab, they questioned whether they had what it takes to be successful in science (psychosocial) and they felt that they were unable to advance their skills (career).

\section{Interpersonal Mismatch}

About a third of the undergraduates in our study $(n=12)$ noted that they did not match their mentors in terms of personality, work style, or communication preferences. Some undergraduates spoke about interpersonal mismatch very generally, noting that they did not "gel well" with their mentors. Others were specific about mismatches. For instance, some undergraduates described how their mentors avoided making eye contact, mumbled during conversation, or appeared to move away from them physically in lab. Other undergraduates described how their mentors' work styles differed from their own, either being more or less structured. For example, one undergraduate contrasted her work style with that of her mentor, noting, "He's so nitpicky and I'm a very 'go with the flow' kind of person." Another explained that the opposite was true for her-she was detail oriented, while her mentor "was scatterbrained, eccentric. She bounced all over the place a lot ... she was disorganized."

Undergraduates commented on how personalities undermined their ability to develop a comfortable relationship. In some cases, these were personality mismatches, such having a mentor who had a volatile personality that they had to "tolerate." In other cases, the undergraduates perceived their mentors' personalities as too similar to their own, which undermined the quality of the relationship. For instance, one undergraduate noted that she and her mentor were both shy, so they never formed a comfortable relationship:

I was too afraid to even say "hi" to him [my mentor] ... That's just me being a shy person, pretty introverted. But I also think he was pretty introverted too, because whenever we were in lab together, he gravitated away from me.

For the most part, undergraduates perceived these experiences as absence of positive mentoring. They expressed disappointment or frustration about mismatches but did not see them as anyone's fault. Because these mismatches prevented undergraduates from developing close working relationships with their mentors, they felt they missed both personal and professional opportunities that would have been possible with a superior match.

\section{Lack of Career and Technical Support}

All of the undergraduates in our sample $(n=33)$ described wanting, needing, or seeking scientific or technical advice or career guidance from their mentors. In some instances, undergraduates wanted to better understand the purpose and value of their research and how it fit into the larger picture of research in the lab or the field. For example, one undergraduate explained, "I was looking for more guidance for understanding the project instead of the little aspects of it, because I'm just told to do one tiny assay, but I have no idea what that is being used for in a bigger picture form." Other undergraduates described wanting to do research that was more tightly aligned with their own interests. By investing their time in research that was uninteresting to them, they felt that they were not developing knowledge or skills that would help them in their own career pursuits.

Some undergraduates attempted to engage their mentors in discussions about graduate school, jobs in science, and other career-related topics such as publishing. They explained how their attempts were rebuffed and how their mentors expected them to find information on their own. One undergraduate described the experience of attempting and failing to get advice from her mentor about how to pursue graduate school:

Nobody that I really knew very well had done grad school and I didn't know what the first steps would be. I went and talked to him. I remember his response was, "Well, you really need to do some looking up for yourself first. You need to decide what you wanna do. Then you can come talk to me and we'll find somebody that matches that project." But I didn't even know where to start looking.

Undergraduates also reported situations in which they needed more technical guidance than their mentors offered. These situations typically manifested as safety risks or concerns. Undergraduates described situations in which they were implementing procedures or protocols or using equipment with little guidance from their mentors, which put the undergraduates or others at risk. Lack of instruction or unclear instruction resulted in unsafe situations or events such as exposure to harmful chemicals, risky use of equipment, or improper handling of animals or samples. One undergraduate recalled an incident in which the mentor accidentally pricked a student volunteer with a syringe:

\begin{abstract}
We were using syringes and needles ... One day, this was this girl's first day volunteering with us. And [my mentor] just didn't give her clear directions, and her hand was slightly in the way. And the grad student [mentor] was the one that accidentally pricked her with the needle. But then she yelled at the volunteer for it, as if it was [the volunteer's] fault, when really it was the grad student's fault not being careful ... We are working with a vaccine. And it wasn't a contaminated needle, but it could have been.
\end{abstract}

Collectively, undergraduates experienced these situations as missed opportunities to learn from their mentors, rather than actively harmful actions by their mentors. They expected their mentors to look out for them in the lab by teaching them proper techniques and safe application of procedures and as they made decisions about their education and career paths. Undergraduates viewed these experiences as poor investments of their own time that they could be investing in ways that were more fruitful for their professional development.

\section{Lack of Psychosocial Support}

The majority of undergraduates in our sample $(n=19)$ described wanting more encouragement and support from their 
mentors and expressed concern about their mentors' lack of approachability. Lack of psychosocial support manifested mainly in the quality of the mentoring relationship, such as lack of closeness, trust, responsiveness, reciprocity, or mutual respect. These situations occurred when undergraduates perceived that mentors were not invested in their work, them as people, or in their mentoring relationships and thus failed to provide motivation, reassurance, appreciation, or affirmation. Undergraduates perceived these experiences as invalidating, especially when they perceived they had invested a lot of time, effort, and intellect into their research and were not getting anything in return. Undergraduates felt they "weren't good enough" and that their mentors "didn't care about them." For example, one undergraduate described how lack of appreciation from her mentor ultimately undermined her confidence:

I would say she [my mentor] was incredibly demanding ... I think I was putting in a lot for getting very little results back and very little appreciation. After a while it gets to someone. I constantly felt like I wasn't good enough and I wasn't doing good enough research and my understanding capability was low. I was feeling these things because I wasn't getting any support or validation. I mean, maybe once or twice she was nice, and she would say "good work," but for the most part, it was just a really negative experience.

Although some undergraduates indicated that they would have appreciated more verbal encouragement, others indicated that their mentors could have acted in ways that demonstrated greater support. For example, one undergraduate interpreted her mentor's failure to show up for a program event as a lack of support:

[My mentor] told me, "Oh I know there's a [program] breakfast." I was like, "Oh, okay, yes." I took him a thank-you gift, but he didn't show up. It was the little things where I didn't feel there was mutual support to help the relationship.

Undergraduates described instances when mentors explicitly stated that they did not trust undergraduates with particular equipment, techniques, samples, or data, leading them to feel insulted or unmotivated. Undergraduates also described mentors who were unapproachable, such as faculty who physically shut themselves off behind a closed office door or graduate students who wore headphones. Undergraduates perceived these experiences as an implicit signal that their mentors did not want to talk with them and generally were intimidated by mentors who were physically close by (i.e., distinct from absenteeism) but interpersonally distant. One undergraduate explained about her faculty mentor that "he has his own separate office and the door is always closed... I don't want to approach the boss's office with a concern or complaint ... that seems even more intimidating."

Undergraduates reported other mentor behaviors that prevented the development of trusting relationships, such as mentors giving unsolicited advice on lab members' personal lives, sharing intimate details of their own personal lives, and insulting or gossiping about lab members. Although undergraduates were not direct targets of these comments, these situations created an air of discomfort in the lab that made them feel ill at ease with their mentors. Undergraduates who experienced a lack of psychosocial support expressed regret over missed opportunities to build close relationships with their mentors.

\section{Misaligned Expectations}

The majority of undergraduates in our sample $(n=23)$ described various ways that their mentors had unspoken or unreasonable expectations or expectations that were out of alignment with their own. We use the term "misaligned" to reflect how all of these experiences appeared to involve a disconnect between what the mentor and mentee expected from the research experience or the lack of calibration of mentor expectations to mentee knowledge, skills, and abilities. In some cases, undergraduates and their mentors had not clearly communicated or negotiated their mutual expectations, which prompted the undergraduates to feel disappointed that their expectations had not been met. In other cases, undergraduates described situations in which their mentors' expectations were unreasonable. For example, undergraduates expected to be able to balance research, academic, and personal commitments, but found that their mentors expected many more hours than initially advertised. These undergraduates described being pressured to work excessive hours and to prioritize their research over their academics and personal lives, especially if they aspired to be scientists, as one undergraduate described:

The [research] class credit only required like 13-20 hours at most. But I was spending easily 30 hours a week there. And they [my mentors] wanted more. They were constantly like, "You're not dedicated if you're not coming in and going above and beyond." ... They would get upset with me whenever I would take time off to study for tests. They were like, "You know you need to get these things done." ... They were just constantly threatening me with, "You're not dedicated. You're not gonna make it in this field if you're not dedicated. This is what lab work is like. You sleep in the lab." ... She [the lab manager] was very adamant that this is what science was like, that you're there 24/7, and if you're not, then you're not committed. [She] would kind of shame you for not being there.

Other instances of misaligned expectations occurred when undergraduates had ideas about what research would be like that were not aligned with the realities of the work or their project. For example, undergraduates expected to do challenging, intellectually stimulating work and to make speedy research progress, but felt they had not progressed as they hoped or they did not have regular opportunities to learn new things, as one student described, "I was learning a lot the first month ... but then fourth month I was just like, 'okay, I'm doing the same thing.' I guess this is how research is, but still." Even undergraduates who worked on more challenging projects indicated that their mentors would do the thinking for them, rather than letting them have intellectual responsibility for some aspect of the work. They wanted opportunities to troubleshoot or problem solve with advice from their mentors rather than having their mentors solve problems for them, as this undergraduate described:

I think it would have been more productive if we would have gotten our own project, if we would have been given the time to mess up or, I guess, think outside of the box and do our own little thing.... If something went wrong at the lab, he would be 
like, "You know what? I can do it. Don't worry about it," and he would do it. Instead of allowing us to figure out what went wrong and telling us what we did wrong, he would just completely take over and not allow us to do it.

More than half of the undergraduates reported misaligned expectations about how structured their research experiences should be. When their mentors changed schedules multiple times, switched the projects they were working on multiple times, or provided too little oversight, undergraduates struggled to make progress in their research. Mentors who set rigid schedules, for instance, by limiting particular research tasks to specific days and times without apparent justification for doing so, prevented undergraduates from fully participating in the research. Undergraduates also described mentors whose schedules were too fluid, which made it difficult for undergraduates to plan their own schedules and get help from mentors whose schedules kept changing, as this undergraduate explained:

I had set up an appointment for us to go over my abstract, but the day I went to my appointment, he was meeting with somebody else ... it took a bit longer than he expected, so he was like, "Oh, could we just move the meeting?" I was just like, "Okay, that's fine, I just have a deadline." I went there the next meeting and, once again, he was meeting with somebody else. That went on for maybe three times.

Finally, a number of undergraduates felt that their mentors expected them to have the skills and abilities of a graduate student. They reported being given tasks or projects that exceeded their abilities and insufficient instruction to be able to complete them successfully. When their mentors attempted to train them, the training was not targeted at a level they could understand. One undergraduate recalled that his mentor attempted to explain the background of the research, but his explanation was too advanced:

He would be talking very much over my head, and I would try to piece it together. It's one of those things where I just don't think he knew where I was, even though I told him I was a sophomore. ... I think he thought I had more knowledge regarding animal anatomy.

Undergraduates perceived misaligned expectations as being either an actively harmful behavior, such as a mentor setting unreasonably high expectations, or the absence of positive behaviors, such as neglecting to discuss mutual expectations. Students reported experiencing both career-related effects (e.g., being unable to meet with their mentors to receive guidance on the research) and psychosocial effects (e.g., being shamed for not dedicating excessive hours to lab work) of misaligned expectations.

\section{Unequal Treatment}

About a third of the undergraduates in our sample $(n=12)$ described how their mentors did not treat students equally. Undergraduates experienced two main forms of unequal treatment: discrimination and favoritism. Undergraduates perceived being discriminated against because of their personal characteristics and career aspirations. For example, multiple female under- graduates described instances of sexism, in which their mentors treated them differently from their male counterparts. Some instances were more subtle, such as male mentors appearing to be more comfortable engaging in casual, friendly conversation with males in the lab but not females. Other instances were more overt, as this undergraduate recalled from her first day in the lab:

[My mentor] was giving me a tour and he introduced me to my other lab mates. He's like, "Great, we have another female in the lab. Now we have someone to wash the dishes."

Undergraduates also experienced discrimination because of their personal and professional choices, such as wanting to have children or to pursue a career in medicine. One undergraduate recounted that her mentor would allocate less of his time to women whom he thought might have children, which made her fearful of being seen with her boyfriend. A few undergraduates felt that their mentors were biased against students pursuing professional school (e.g., medical school), as this undergraduate explained:

I eventually want to be a doctor, so I think [my mentor] might have thought I wasn't that serious about bench work science as much as I was about that anatomy physiology component of it ... There were certain comments where it was like, "Oh, premeds, they just kind of do research. The real science-y people are the ones that are going to the Ph.D. or the grad programs."

In other cases, undergraduates felt that unequal treatment was arbitrary rather than targeting a particular group. Undergraduates perceived this kind of treatment as favoritism. These situations appeared to occur when there was more than one undergraduate in the research group and the undergraduates observed differences in how they were treated by the faculty mentor, as this undergraduate explains:

If my partner [the other undergraduate] and I were presenting, most of the questions were only focused to me. If I didn't repeat something [the faculty mentor] told me to repeat ten times... Even my partner was like, "Oh he's always putting you on the spot." ... It felt like more than just tough love. There was another incident where somebody else was presenting and everybody was in a meeting... She was presenting a project we were just listening to and he turns around [to me and asks], "Do you understand this?... If you don't understand this, why aren't you asking questions?" I was just like, “Oh, I didn't know we could ask questions. I just thought we could ask questions at the end." ... I saw where he was coming from but at the same time, I was just very placed on the spot where he didn't address my lab partner. It was just me.

Undergraduates perceived unequal treatment as an actively harmful mentor behavior with both psychosocial effects, such as feeling unable to form strong relationships with their mentors, and career effects, such as when their mentors did not invest time and resources into their professional growth.

\section{LIMITATIONS}

This study was designed to qualitatively describe and characterize the negative mentoring experiences of undergraduate life 


Absence of positive
mentoring experiences $\quad \begin{array}{r}\begin{array}{r}\text { Actively harmful } \\ \text { mentoring experiences }\end{array} \\ \begin{array}{|lcr}\hline \text { Interpersonal mismatch } & \text { Absenteeism } & \text { Abuse of power } \\ \text { Lack of career support } & \text { Misaligned expectations } & \text { Unequal treatment } \\ \hline \text { Lack of psychosocial support } & & \\ \hline\end{array}\end{array}$

FIGURE 1. Negative mentoring experiences in undergraduate life science research. Undergraduate life science researchers experienced negative mentoring in seven main ways. They perceived some of these as absence of positive mentoring experiences, such as lack of career and psychosocial support and interpersonal mismatch (left), and others as actively harmful mentoring experiences, such as abuse of power and unequal treatment (right). Undergraduates experienced absenteeism and misaligned expectations (middle) as either absence of positive or actively harmful depending on the severity of the situation.

science researchers. We attempted to maximize the validity of the results by interviewing a diverse group of participants from different institutional types. Yet the undergraduates in our sample are mostly from research-intensive universities with modest enrollment of students from underrepresented backgrounds. Future research should include undergraduates from a more diverse set of institution types, including a greater number of institutions with high enrollment of students from underrepresented backgrounds who may experience forms of negative mentoring not reflected in the current data set (e.g., harassment).

Our study design and methods do not allow us to draw conclusions about the prevalence or frequency of negative mentoring. Future research should aim to quantify negative mentoring and relate it to the outcomes that undergraduate researchers experience, including whether particular types of negative mentoring are more intense or problematic than others. Our methods are also subject to the limitations of recall from the students' perspective. We cannot make any inferences or draw conclusions about the mentors' actual behaviors or the intentions, motivations, or reasoning behind their mentoring approaches or decisions. As noted earlier, we opted to characterize undergraduates' perspectives, because previous research on negative mentoring has demonstrated that mentee perceptions of negative mentoring influence their outcomes (Scandura, 1998; Eby and Allen, 2002; Eby et al., 2008, 2010).

All undergraduates in our study reported experiencing multiple forms of negative mentoring. This may be the result of our screening methods, which may have favored students who had sufficiently poor experiences to rate their mentoring negatively. This may also be the result of an overall negative lab environment allowing multiple forms of negative mentoring to occur. It also may be that certain students are more sensitive to their mentors' behaviors than others. Our study design and methods limit our ability to account for contextual factors (e.g., general lab environment) or student characteristics (e.g., sensitivity or emotional stability; Turban and Dougherty, 1994; Turban and Lee, 2007). Further research is necessary to determine the influence of these factors on how students perceive negative mentoring experiences and are affected by them.

\section{DISCUSSION}

Here we provide the first systematic characterization of negative mentoring that undergraduate life science researchers experience. In contrast to Scandura's dysfunctional mentoring framework (Scandura, 1998), in which mentors were perceived as having good or bad intent, the undergraduates in our study perceived negative experiences as missed opportunities to fully reap the benefits of their relationships with their mentors (i.e., absence of positive mentoring experiences) or as actively harmful experiences that undermined their confidence, their selfworth, and their interest in or motivation to continue in science (Figure 1). Furthermore, unlike the dichotomy put forth in Scandura's dysfunctional mentoring framework (Scandura, 1998), mentees in our study perceived virtually all negative mentoring experiences as having both psychosocial and career-related effects. For instance, the undergraduates in our study regularly perceived poor interactions with mentors as signs that they were not to be trusted with research tasks or that they were not good enough to be scientists. This not only undermined their confidence (i.e., psychosocial outcome) but also made them question their career choices (i.e., career outcome). This finding is consistent with social cognitive theories that assert the importance of self-efficacy and other psychosocial phenomena (e.g., identity development) in career decision making (Lent et al., 1994; Bandura, 1997). Additional research is needed to understand whether and how negative mentoring experiences influence undergraduate researchers' career choices and, if so, whether shifts in self-efficacy or other psychosocial factors are the mechanism of influence. Longitudinal-study designs may be particularly fruitful for examining the dynamic relationships among undergraduate researchers' experiences with negative mentoring, their psychosocial development, and their career choices.

Our results show that undergraduates experience forms of negative mentoring that appear unique to their stage of development and to the context of academic research. The undergraduates in our study approached their research experiences as learning opportunities, even when they did not intend to pursue research as a career (e.g., they identified as "pre-med"). Because undergraduates often participate in research as part of a degree or educational program, it is reasonable to expect that UREs and associated mentoring would be designed to foster learning. This expectation may contrast to some extent with mentoring in the workplace, where employees have access to formal job training and are expected to bring some level of skill and knowledge to the job and to operate more independently. For example, mentor unavailability manifests as neglect in the workplace (Eby et al., 2000) and as absenteeism in UREs. While employees may sometimes receive insufficient attention from their mentors, the complete physical absence of mentors due to fieldwork, attending conferences, presenting talks at other institutions, and so on is unique to academic research and may 
have more severe consequences for undergraduates, who are likely to be less ready to work independently at this early career stage. Because these situations are commonplace in academic research, steps should be taken to ensure that undergraduate researchers are not forgotten. One strategy that is already commonly practiced is to identify additional mentors, such as graduate students or postdoctoral associates, who are knowledgeable about the undergraduates' research and interested and willing to help them in addition to or in place of a faculty mentor. Results from this study and our prior research indicate that it is important that faculty mentors remain engaged in mentoring undergraduate researchers to provide high-level direction, feedback, and support and to maximize undergraduate researchers' outcomes (Aikens et al., 2016, 2017; Joshi et al., 2019).

In light of the differences between workplace and academic mentoring, mentors could provide more structure to UREs, for instance, by creating syllabi, articulating learning objectives and connecting them to research-related assignments (e.g., reading papers, presenting group meetings, performing experiments, analyzing data, troubleshooting), and systematically using both low-stakes formative assessments (e.g., lab notebook checks, group meeting discussions, annotated bibliographies of seminal papers) and higher-stakes summative assessments (e.g., final papers, posters, or presentations). These strategies have the potential to clarify expectations, ensure equitable treatment of undergraduate researchers, and ensure that undergraduates have the career and technical support they need. There are curricula that can provide this structure for cohorts of undergraduate researchers (e.g., Balster et al., 2010). Practically, these curricula may be seen as cutting into valuable research time, which is important to acknowledge, because many mentors of undergraduate researchers are not recognized or compensated for the time, energy, and resources they invest in meaningfully involving undergraduates in research (Baker et al., 2015; Morales et al., 2017). For instance, funding for undergraduate research programs typically includes stipends for the undergraduates but little if any funding for the scientific work, which has real costs that the research lab must bear, especially in "wet lab" research. Additional work is needed to determine the amount and types of structure that are necessary and sufficient to reduce or, ideally, prevent negative mentoring experiences, while allowing enough time for research to make the experience worthwhile for both undergraduates and their mentors.

Notably, the negative mentoring experienced by undergraduates in this study reflects issues that are addressed in Entering Mentoring, an established professional development curriculum on research mentoring (Handelsman, 2005). This curriculum offers guidance on how to align mentor and mentee expectations and assess mentee understanding, which has the potential to prevent misaligned expectations. Entering Mentoring also offers guidance on fostering equity and inclusion and communicating effectively, which could support mentors and mentees in overcoming interpersonal mismatches and addressing situations of unequal treatment. A quasi-experimental study of this curriculum showed that participating in mentoring professional development improves mentoring competence from both the mentor and mentee perspective (Pfund et al., 2014). Future research should directly examine whether negative mentoring experiences can be reduced or prevented by mentor professional development. Future research should also explore whether helping undergraduate researchers to "mentor up" by taking a more active role in managing their relationships with their mentors can equip them with strategies and know-how to avoid or respond to negative mentoring experiences (Lee et al., 2015). Until this research can be done, our findings suggest that negative mentoring experiences might be reduced if mentors:

- Articulate their expectations for the undergraduate's research experience, invite undergraduates to articulate their own expectations, negotiate expectations to achieve some alignment, and revisit expectations periodically to ensure continued alignment.

- Make sure they are available with some regularity in order to provide support, feedback, and guidance, including technical guidance, safety instruction, and education and career advice as well as higher-level guidance of how the undergraduate's research fits into a larger scientific picture.

- Find ways to provide encouragement to mentees, especially when things go wrong. This can take the form of sharing personal experiences of having things go wrong during research, as undergrads may not have experience navigating the ambiguity and failures associated with research.

- Reflect on how their behaviors may be perceived by mentees. A comment that may be intended as a suggestion may be perceived as a directive because of the power differential between mentors and mentees.

As noted earlier, this study focused on the students' perceptions of their mentoring experiences and remained agnostic to the mentors' intentions, because how mentees perceive mentoring ultimately influences their experiences and outcomes, regardless of mentor intent. The purpose of this work is not to criticize mentors, but rather to illuminate ways that mentoring is being experienced by students, because mentors may be unaware that their behaviors are perceived negatively or they may have good intentions or valid reasons for their behaviors. For instance, mentors may feel that they are justified in setting expectations of long work hours, because they believe this is the way to be successful in science. However, excessive work time has been linked to many negative outcomes (Clark et al., 2016), raising questions about whether this behavior should be held as a standard to which undergraduates should aspire. In general, mentors could use these results to reflect on how their behaviors might be perceived by their undergraduate researchers, including which behaviors should be changed or need to be explained to minimize negative perceptions. It is important to note that individual mentors should not be expected to offer the full suite of mentoring support that was absent for undergraduates in this study. Ideally, an undergraduate, or any mentee, should have access to a range of support, including task-oriented guidance, more general professional development, career guidance, emotional support, role modeling, and professional networking (Eby et al., 2013). Scholars of mentoring in other settings have long acknowledged that any single mentor is unlikely to fulfill every mentoring function, and they have recommend that mentees seek out a number of different mentors to fulfill different needs (Baugh and Scandura, 1999; De Janasz and Sullivan, 2004; Allen and Eby, 2010). Tools such as mentoring maps and 
individual development plans adapted for URE contexts may be useful for helping undergraduate researchers and their research mentors identify a suitable group of mentors (Ragins and Kram, 2007; Clifford et al., 2013; Gould, 2017).

Undergraduates in our study indicated that they had no safe avenue for reporting negative mentoring behaviors. In fact, several reported they were discouraged from reporting or feared repercussions of doing so. Although it is premature to make firm recommendations based on our small sample, there are practical supports that could be put in place to address these issues. For example, mentors could ask mentees for periodic feedback on how the mentor could better support the mentee. Because mentees will not always feel comfortable giving honest feedback to someone who is in a position of power, departments and institutions could establish and publicize anonymous reporting systems or appoint ombudspersons as points of contact for undergraduates to report mentoring concerns. Such systems would enable identification of patterns of problematic mentor behaviors, especially illegal behaviors (e.g., discrimination), which could then be investigated further. In addition, processes need to be developed to provide feedback to mentors so they can improve their mentoring while protecting mentees.

Our study is not designed to yield insight into the prevalence, causes, or effects of negative mentoring experiences. A more scalable approach to data collection and analysis is needed to determine how widespread negative mentoring is, how particular forms of negative mentoring affect undergraduate researchers, and whether negative mentoring disproportionately affects students from different backgrounds. Our results should be helpful in defining the content domain of "negative mentoring in undergraduate research," which is a first step in developing a quantitative measure of it (American Educational Research Association, American Psychological Association, National Council on Measurement in Education, Joint Committee on Standards for Educational, and Psychological Testing (US), 2014). A quantitative measure could be used to study the prevalence and impact of negative mentoring in a larger and more generalizable sample. Such a measure could also be used to determine the extent to which undergraduates with diverse personal characteristics (e.g., gender, race, first-generation or transfer status) experience different forms or levels of negative mentoring or are differentially affected by these experiences. Finally, a quantitative measure of negative mentoring could be used to test the effectiveness of interventions (e.g., mentor professional development, mentoring up programming) that are designed to reduce or prevent negative mentoring and its impacts.

\section{ACKNOWLEDGMENTS}

We thank all of our participants for their responses and the many individuals who helped with distributing the study information. We also thank Benjamin Hultquist, Kathren Sage Royston, and the UGA Biology Education Research Group for their feedback on earlier drafts of the article. This material is based upon work supported in part by the National Science Foundation (NSF) under grant number 1659423, which provided undergraduate research stipends for authors T.T.T. and D.E. Any opinions, findings, and conclusions or recommendations expressed in this paper are those of the authors and do not necessarily reflect the views of the NSF. Additional support for this work was provided by the Georgia Athletic Association Professorship in Innovative Science Education and the UGA Department of Biochemistry and Molecular Biology and Franklin College of Arts and Sciences.

\section{REFERENCES}

Aikens, M. L., Robertson, M. M., Sadselia, S., Watkins, K., Evans, M., Runyon, C. R., ... \& Dolan, E. L. (2017). Race and gender differences in undergraduate research mentoring structures and research outcomes. CBE-Life Sciences Education, 16(2), ar34. https://doi.org/10.1187/cbe.16-07-0211

Aikens, M. L., Sadselia, S., Watkins, K., Evans, M., Eby, L., \& Dolan, E. L. (2016). A social capital perspective on the mentoring of undergraduate life science researchers: An empirical study of undergraduate-postgraduate-faculty triads. CBE-Life Sciences Education, 15(2), ar16. https:// doi.org/10.1187/cbe.15-10-0208

Allen, T. D., \& Eby, L. T. (Eds.). (2010). The Blackwell handbook of mentoring A multiple perspectives approach. West Sussex, UK: John Wiley \& Sons.

American Association for the Advancement of Science. (2011). Vision and change in undergraduate biology education: A call to action. Washington, DC: National Academies Press.

American Educational Research Association, American Psychological Association, National Council on Measurement in Education, Joint Committee on Standards for Educational, \& Psychological Testing (US). (2014). Standards for educational and psychological testing. Washington, DC.

Baker, V. L., Pifer, M. J., Lunsford, L. G., Greer, J., \& Ihas, D. (2015). Faculty as mentors in undergraduate research, scholarship, and creative work: Motivating and inhibiting factors. Mentoring \& Tutoring: Partnership in Learning, 23(5), 394-410.

Balster, N., Pfund, C., Rediske, R., \& Branchaw, J. (2010). Entering research: A course that creates community and structure for beginning undergraduate researchers in the STEM disciplines. CBE-Life Sciences Education, 9(2), 108-118. https://doi.org/10.1187/cbe.09-10-0073

Bandura, A. (1997). Self-efficacy: The exercise of control. New York: Freeman

Baugh, S. G., \& Scandura, T. A. (1999). The effect of multiple mentors on protégé attitudes toward the work setting. Journal of Social Behavior and Personality, 14(4), 503-522.

Bernier, A., Larose, S., \& Soucy, N. (2005). Academic mentoring in college: The interactive role of student's and mentor's interpersonal dispositions. Research in Higher Education, 46(1), 29-51. https://doi.org/10.1007/ s11162-004-6288-5

Byars-Winston, A. M., Branchaw, J., Pfund, C., Leverett, P., \& Newton, J. (2015). Culturally diverse undergraduate researchers' academic outcomes and perceptions of their research mentoring relationships. International Journal of Science Education, 37(15), 2533-2554. https:// doi.org/10.1080/09500693.2015.1085133

Charmaz, K. (2006). Constructing grounded theory: A practical guide through qualitative analysis. Thousand Oaks, CA: Sage.

Chen, X. (2013). STEM Attrition: College Students' Paths into and out of STEM Fields. Statistical Analysis Report (NCES 2014-001). Retrieved April 18 2017, from https://eric.ed.gov/?id=ED544470

Clark, M. A., Michel, J. S., Zhdanova, L., Pui, S. Y., \& Baltes, B. B. (2016). All work and no play? A meta-analytic examination of the correlates and outcomes of workaholism. Journal of Management, 42(7), 1836-1873. https://doi.org/10.1177/0149206314522301

Clifford, P. S., Fuhrmann, C. N., Lindstaedt, B., \& Hobin, J. A. (2013). An individual development plan will help you get where you want to go. The Physiologist, 56(2), 43

Cortina, L. M., Magley, V. J., Williams, J. H., \& Langhout, R. D. (2001). Incivility in the workplace: Incidence and impact. Journal of Occupational Health Psychology, 6(1), 64

Creswell, J. W. (2012). Qualitative inquiry and research design: Choosing among five approaches. Thousand Oaks, CA: Sage.

De Janasz, S. C., \& Sullivan, S. E. (2004). Multiple mentoring in academe: Developing the professorial network. Journal of Vocational Behavior, 64(2), 263-283.

Dolan, E., \& Johnson, D. (2010). The undergraduate-postgraduate-faculty triad: Unique functions and tensions associated with undergraduate 
research experiences at research universities. CBE-Life Sciences Education, 9(4), 543-553.

Duck, S. (1994). Stratagems, spoils and the serpent's tooth: On the delights and dilemmas of personal relationships. In The dark side of interpersonal communication (pp. 3-24). Hillsdale, NJ: Erlbaum.

Eby, L. T., \& Allen, T. D. (2002). Further investigation of protégés' negative mentoring experiences: Patterns and outcomes. Group \& Organization Management, 27(4), 456-479. https://doi.org/10.1177/1059601102238357

Eby, L. T., Allen, T. D., Hoffman, B. J., Baranik, L. E., Sauer, J. B., Baldwin, S., .. \& Evans, S. C. (2013). An interdisciplinary meta-analysis of the potential antecedents, correlates, and consequences of protégé perceptions of mentoring. Psychological Bulletin, 139(2), 441-476. https://doi.org/ 10.1037/a0029279

Eby, L. T., Butts, M. M., Durley, J., \& Ragins, B. R. (2010). Are bad experiences stronger than good ones in mentoring relationships? Evidence from the protégé and mentor perspective. Journal of Vocational Behavior, 77(1) 81-92. https://doi.org/10.1016/j.jvb.2010.02.010

Eby, L. T., Durley, J. R., Evans, S. C., \& Ragins, B. R. (2008). Mentors' perceptions of negative mentoring experiences: Scale development and nomological validation. Journal of Applied Psychology, 93(2), 358.

Eby, L., McManus, S. E., Simon, S. A., \& Russell, J. E. A. (2000). The protege's perspective regarding negative mentoring experiences: The development of a taxonomy. Journal of Vocational Behavior, 57(1), 1-21. https:// doi.org/10.1006/jvbe.1999.1726

Estrada, M., Hernandez, P. R., \& Schultz, P. W. (2018). A longitudinal study of how quality mentorship and research experience integrate underrepresented minorities into STEM careers. CBE-Life Sciences Education, 17(1), ar9. https://doi.org/10.1187/cbe.17-04-0066

Estrada, M., Woodcock, A., Hernandez, P. R., \& Schultz, W. P. (2011). Toward a model of social influence that explains minority student integration into the scientific community. Journal of Educational Psychology, 103(1) 206-222. https://doi.org/10.1037/a0020743

Fontana, A., \& Frey, J. H. (2000). The interview: From structured questions to negotiated text. In Denzin, N. K., \& Lincoln, Y. S. (Eds.), Handbook of qualitative research (2nd ed., pp. 645-672). Thousand Oaks, CA: Sage.

Goodyear, R. K., Crego, C. A., \& Johnston, M. W. (1992). Ethical issues in the supervision of student research: A study of critical incidents. Professional Psychology: Research and Practice, 23(3), 203-210. https:// doi.org/10.1037/0735-7028.23.3.203

Gould, J. (2017). Career development: A plan for action. Nature, 548(7668) 489-490

Handelsman, J. (2005). Entering mentoring: A seminar to train a new generation of scientists. Madison: Board of Regents of the University of Wisconsin System

Harsh, J. A., Maltese, A. V., \& Tai, R. H. (2011). Undergraduate research experiences from a longitudinal perspective. Journal of College Science Teaching, 41(1), 84.

Hernandez, P. R., Estrada, M., Woodcock, A., \& Schultz, P. W. (2017). Mentor qualities that matter: The importance of perceived (not demographic) similarity. Journal of Experimental Education, 85(3), 450-468. https:// doi.org/10.1080/00220973.2016.1246405

Hsieh, H.-F., \& Shannon, S. E. (2005). Three approaches to qualitative content analysis. Qualitative Health Research, 15(9), 1277-1288. https://doi. org/10.1177/1049732305276687

Hurtado, S., Cabrera, N. L., Lin, M. H., Arellano, L., \& Espinosa, L. L. (2008) Diversifying science: Underrepresented student experiences in structured research programs. Research in Higher Education, 50(2), 189-214. https://doi.org/10.1007/s11162-008-9114-7

Hurtado, S., Eagan, M. K., Tran, M. C., Newman, C. B., Chang, M. J., \& Velasco, P. (2011). "We do science here": Underrepresented students' interactions with faculty in different college contexts. Journal of Social Issues, 67(3), 553-579. https://doi.org/10.1111/j.1540-4560.2011.01714.x

Joshi, M., Aikens, M. L., \& Dolan, E. L. (2019). Direct ties to a faculty mentor related to positive outcomes for undergraduate researchers. BioScience, 69(5), 389-397. https://doi.org/10.1093/biosci/biz039

Kram, K. E. (1983). Phases of the mentor relationship. Academy of Management Journal, 26(4), 608-625. https://doi.org/10.2307/255910
Kram, K. E. (1985). Mentoring at work. Glenview, IL: Scott Foresman.

Laursen, S., Hunter, A.-B., Seymour, E., Thiry, H., \& Melton, G. (2010). Undergraduate research in the sciences: Engaging students in real science. San Francisco, CA: Wiley.

Lee, S. P., McGee, R., Pfund, C., \& Branchaw, J. (2015). Mentoring up: Learning to manage your mentoring relationships. The mentoring continuum From graduate school through tenure. Syracuse, NY: Graduate School Press of Syracuse University.

Lent, R. W., Brown, S. D., \& Hackett, G. (1994). Toward a unifying social cognitive theory of career and academic interest, choice, and performance. Journal of Vocational Behavior, 45(1), 79-122. https://doi.org/10.1006/ jvbe.1994.1027

Lincoln, Y. S., \& Guba, E. G. (1985). Establishing trustworthiness. Naturalistic Inquiry, 289, 331.

Lopatto, D., \& Tobias, S. (2010). Science in solution: The impact of undergraduate research on student learning. Washington, DC: Council on Undergraduate Research.

Morales, D. X., Grineski, S. E., \& Collins, T. W. (2017). Faculty motivation to mentor students through undergraduate research programs: A study of enabling and constraining factors. Research in Higher Education, 58(5), 520-544.

Morse, J. M., Barrett, M., Mayan, M., Olson, K., \& Spiers, J. (2002). Verification strategies for establishing reliability and validity in qualitative research International Journal of Qualitative Methods, 1(2), 13-22. https:// doi.org/10.1177/160940690200100202

National Academies of Sciences, Engineering, and Medicine. (2017). Undergraduate research experiences for STEM students: Successes, challenges, and opportunities. Washington, DC: National Academies Press. https:// doi.org/10.17226/24622

Pfund, C., House, S. C., Asquith, P., Fleming, M. F., Buhr, K. A., Burnham, E. L., ... \& Sorkness, C. A. (2014). Training mentors of clinical and translational research scholars: A randomized controlled trial. Academic Medicine: Journal of the Association of American Medical Colleges, 89(5), 774782. https://doi.org/10.1097/ACM.0000000000000218

Ragins, B. R., Cotton, J. L., \& Miller, J. S. (2000). Marginal mentoring: The effects of type of mentor, quality of relationship, and program design on work and career attitudes. Academy of Management Journal, 43(6), 1177-1194. https://doi.org/10.2307/1556344

Ragins, B. R., \& Kram, K. E. (2007). The roots and meaning of mentoring. In Ragins, B. R., \& Kram, K. E. (Eds.), The handbook of mentoring at work: Theory, research, and practice (pp. 3-15). Thousand Oaks, CA: Sage.

Saldana, J. (2015). The coding manual for qualitative researchers. Thousand Oaks, CA: Sage.

Scandura, T. A. (1998). Dysfunctional mentoring relationships and outcomes. Journal of Management, 24(3), 449-467. https://doi.org/10.1016/ S0149-2063(99)80068-3

Schilpzand, P., De Pater, I. E., \& Erez, A. (2016). Workplace incivility: A review of the literature and agenda for future research. Journal of Organizational Behavior, 37(S1)

Simon, S. A., \& Eby, L. T. (2003). A typology of negative mentoring experiences: A multidimensional scaling study. Human Relations, 56(9), $1083-$ 1106. https://doi.org/10.1177/0018726703569003

Tepper, B., Simon, L., \& Park, H. M. (2017). Abusive supervision. Annual Review of Organizational Psychology and Organizational Behavior, 4, 123-152.

Tepper, B. J. (2000). Consequences of abusive supervision. Academy of Management Journal, 43(2), 178-190

Thiry, H., \& Laursen, S. L. (2011). The role of student-advisor interactions in apprenticing undergraduate researchers into a scientific community of practice. Journal of Science Education and Technology, 20(6), 771-784. https://doi.org/10.1007/s10956-010-9271-2

Turban, D. B., \& Dougherty, T. W. (1994). Role of protégé personality in receipt of mentoring and career success. Academy of Management Journal, 37(3), 688-702. https://doi.org/10.2307/256706

Turban, D. B., \& Lee, F. K. (2007). The role of personality in mentoring relationships. In Ragins, B. R., \& Kram, K. E. (Eds.), The handbook of mentoring at work: Theory, research, and practice (pp. 21-50). Thousand Oaks, CA: Sage. 